\section{Transobturator tension-free vaginal tape is the most common procedure in women with stress urinary incontinence: our experience}

\author{
Barbara Cristina Gentile, \\ Roberto Giulianelli, Luca Albanesi, \\ Gabriella Mirabile, Francesco Pisanti \\ Department of Urology, Nuova Villa \\ Claudia, Rome, Italy
}

\section{Abstract}

Transobturator tension-free vaginal tape (TVT-0) surgery is currently one of the most effective procedures used to treat women with stress urinary incontinence (SUI), however, long-term follow-up data in medical literature is scarce. For this study, we enrolled women with SUI assessed by an urodynamic examination and a translabial ultrasound with a pelvic organ prolapse no greater than grade 2 . All of the women were also given a pre- and postoperative test to assess their quality of life. They were given a thorough physical examination, asked to keep a voiding diary, and underwent an urodynamic examination and a translabial ultrasound. Additionally, we also further evaluated intraoperative and postoperative complications and the onset of de novo detrusor overactivity after the procedure. We also assessed the long-term efficacy of the TVT-0 in those women with SUI caused by sphincter hypotonia. All of the women underwent TVT-0 surgery without any associated procedure. Our findings indicate that TVT-0 surgery is an effective treatment option for women with SUI, showing a very high cure rate and a low incidence of complications, with sustained outcomes even in the long-term. However, in women with SUI caused by sphincter hypotonia, the excellent outcomes in early stages tend to dwindle over time.

\section{Introduction}

Over the years many theories have been proposed about the complex anatomical and physiological aspects involved in the continence mechanism. ${ }^{1-3}$ Surgical treatment of stress urinary incontinence (SUI) remains to date the treatment of choice for patients where a conservative approach has failed. Several factors should be considered when choosing a good surgery for patients suffering from stress urinary incontinence (age, expectations, comorbidities, previous surgery, severity of symptoms, risk of complications, duration of stay, etc.). Several studies comparing the retropubic and transobturator techniques have demonstrated that there is no difference in terms of healing at 12 months, ${ }^{4,5}$ but the retropubic method appears to be associated with a higher rate of complications. To date, however, only a few studies have evaluated the long-term efficacy of transobturator tensionfree vaginal tape (TVT-0) surgery.

The purpose of this study was to evaluate the long-term effectiveness in terms of outcomes and quality of life, with a mean followup time of at least three years (up to seven years). Over the course of the study we evaluated the results in subjective terms [International Consultation on IncontinenceShort Form (ICIQ-SF)], the maintenance of the outcomes (stress test) and adverse events. A multivariate analysis was performed to investigate the results.

\section{Materials and Methods}

In our institute, from January 2006 to January 2010, 84 women with SUI were enrolled in the study. The median age was 65.3 years (51-76 years). Three patients were lost during the first follow-up and one patient was released from the studio for a subsequent diagnosis of Parkinson's disease.

All patients underwent thorough examination of their medical history, voiding diary, and a physical examination was performed with the patient in the lithotomy position and the pelvic organ prolapse (POP) was described during a maximal Valsalva maneuver according to the pelvic organ prolapse quantification (POP-Q) recommended by the International Continence Society (ICS). Written informed consent was obtained.

Urethral hypermobility was determined using the Q-tip test $>30$. In addition, all patients had a urinalysis with urine culture, urodynamic examination [uroflowmetry, filling cystomanometry, Valsalva leak point pressure (VLPP)/flow study] and a translabial ultrasound. Translabial ultrasound provides the most sensitive assessment of the degree of urethral mobility by measuring the pubo-urethral distance and angle. Also the translabial ultrasound is useful in determining detrusor wall thickness, and in assessing pelvic organ prolapse as well as levator function and anatomy and can reveal urethral diverticula, cysts, or neoformation in the lumen. These women then subsequently underwent TVT-0 surgery. All of the women with overactive bladder $(\mathrm{OAB})$, severe detrusor hypocontractility, cervico-urethral obstruction with post-voiding residual $>100 \mathrm{~mL}$, vaginal prolapse greater than 2 according to the POP-Q system were
Correspondence: Barbara Cristina Gentile, Department of Urology, Nuova Villa Claudia, via Flaminia Nuova 280, Rome, Italy.

Tel.: +39.338 .8664907 - Fax: +39.06 .87132680 .

E-mail: bcgentile@libero.it

Key words: stress urinary incontinence, tension free vaginal tape.

Received for publication: 16 December 2014. Revision received: 8 September 2014.

Accepted for publication: 19 September 2014

This work is licensed under a Creative Commons Attribution NonCommercial 3.0 License (CC BYNC 3.0).

(C) Copyright B.C. Gentile et al., 2014

Licensee PAGEPress, Italy

Urogynaecologia 2014; 28:158

doi:10.4081/uij.2014.158

excluded. Patients were included regardless of the Q-tip test and VLPP values. All methods, definitions and units were updated in accordance with the latest International Continence Society report on the standardization of terminology. ${ }^{6}$ All patients also filled in ICIQ-SF. ${ }^{7}$

Of these 80 SUI patients, 19 had severe stress urinary incontinence associated with sphincter deficiency and a loss of urine with minimal abdominal pressures less than $60 \mathrm{~cm}$ $\mathrm{H}_{2} \mathrm{O}$.

All TVT-0 procedures were performed according to the technique originally described by de Leval. ${ }^{8}$

A flowchart describing the initial recruitment numbers and the numbers of patients which attended each follow up (Figure 1) Postoperative checks were performed at one month, six months and annually thereafter. The check at one month included medical history, physical examination, voiding diary, stress testing and an evaluation of the patient's subjective satisfaction. The stress test was performed in the standing position with a full bladder (ultrasound volume $\geq 400$ $\mathrm{mL}$ ). The patients also underwent a complete urine test and a uroflowmetry to assess postvoid residual. The checks at 6 months and annually involved the patient undergoing a urodynamic examination, a translabial ultrasound, the ICIQ-SF, ${ }^{9}$ and a quality of life (QoL) assessment, in addition to the complete urine test. The translabial ultrasound is the only imaging method capable of visualizing modern slings. So this technique can relieve a non-correct position of the sling or their migration. Nobody patients had at the follow up migration or no correct position of the sling. Participants would be reviewed by one doctor of the team of our Department, not always the surgeon who performed the procedure. 
Healing was determined according to the lack of urine leakage during the various stress tests. The same patients were also asked to provide a subjective satisfaction score to the outcome on a scale ranging from very much improved, much improved, slightly improved or not improved (PGI-I $\leq 2$ ). The mean operative time was $18.5 \mathrm{~min}$. All patients who underwent TVT-0 were discharged on the day following the operation.

\section{Statistical analysis}

The statistical analysis was performed with SPSS v.17 for Windows (IBM Corp., Armonk, NY, USA). Continuous variables were reported as median and interquartile range. Chi-square and Fisher's exact test were used to analyze proportions depending on the case. The logrank test was used for univariate analysis of variables that had the potential to affect the risk of recurrent SUI (subjective and objective). For this purpose, continuous variables were dichotomized arbitrarily according to their definition (elderly: age $\geq 65$ years, obese: body mass index $\geq 30 \mathrm{~kg} / \mathrm{m}^{2}$, multiparous women with two or more vaginal births, urethral hypermobility with Q-tip test $>30$, and intrinsic sphincter deficiency with VLPP $<60$ $\mathrm{cm} \mathrm{H}_{2} 0$ ). All nominal variables were dichotomized as yes/no.

All covariates with significant correlation or a tendency towards association $(\mathrm{P} \leq 0.20)$ in univariate analysis with the outcome of interest (subjective and objective SUI recurrence) were performed for the multivariate analysis using the Cox proportional hazards model to select independent predictors.

Finally, the univariate and multivariate analyses were performed to investigate the factors that influence the risk of developing $d e$ novo $\mathrm{OAB}$.

\section{Results}

The patients' characteristics are summarized in Table 1.

There were no intraoperative complications except for one case of vaginal bleeding, which was resolved by manual compression and placing Tabotamp in the vaginal tunnel, and which did not require any blood transfusion.

The follow up time was minimum 6 months and maximum 36 months (Figure 1).

Eleven cases of postoperative cervico-urethral obstruction were recorded in the followup which necessitated placement of a catheter for post-void residual greater than $100 \mathrm{~mL}$, which, however, was resolved seven days after catheter removal in eight patients, whereas sling removal was necessary from three of the patients. These patients we removed from the study.
Urodynamic assessment was repeated at 6 month following surgery and at 1,2 and 3 year. The cure rate, about the SUI, was $91.02 \%$ at one year and $87.01 \%$ at three years, which means that TVT-0 seems to stand the test of time. No patient complained of dyspareunia.

Unfortunately the occurrence of de novo OAB symptoms was reported in $27 \%$ and $21 \%$ of patients at the 1 and 3-year follow-up, respectively. We have not found any association between the occurrence de novo $\mathrm{OAB}$ and characteristics of the patients, however, there is a higher incidence in those patients who developed a postoperative cervico-urethral obstruction (in the 11 patients who necessitated placement of a catheter 7 patients presented $\mathrm{OAB}$ de novo) but our numbers are too small to draw conclusions. It will be useful in the future a study in this regard. All patients received treatment with antimuscarinics. Of these, $55 \%$ were subjectively cured.
Neuromodulation via posterior tibial nerve stimulation was performed on non-responder patients.

The patients showed improvement in QoL score in the post operative and this result was confirmed in every follow up. We noticed a significant difference in women with sphincter hypotonia who underwent TVT-0 surgery. The results obtained from these patients one month after the procedure were not the same as those reported at one year and three years. At the first follow-up visit, all patients with urinary incontinence caused by sphincter hypotonia (determined by the urodynamic examination with VLPP $<60 \mathrm{~cm} \mathrm{H}_{2} \mathrm{O}$ ) were completely dry, but we removed the sling in two of these patients on account of a high post-void residual that could not be improved with alphalytic therapy. At one year, seven out of 17 patients reported the reappearance of mild incontinence (loss of a few drops under stress). At

Table 1. Baseline characteristics.

\begin{tabular}{lc} 
Characteristics & $\mathrm{N}=84$ \\
Age, year (median IQR) & $65.3(51-76)$ \\
$\mathrm{BMI}, \mathrm{kg} / \mathrm{m}^{2}$ (median IQR) & $25(22.4-29.1)$ \\
\hline Sexually active (\%) & $52(61.9)$ \\
Menopausal (\%) & $67(79.7)$ \\
\hline Smoking habits (\%) & $12(14.2)$ \\
Previous vaginal deliveries (median IQR) & $2(1-2)$ \\
\hline Previous hysterectomy (\%) & $7(8.3)$ \\
Previous POP surgery (\%) & $5(5.9)$ \\
\hline Previous anti-incontinence procedures & $4(4.7)$ \\
\hline
\end{tabular}

107 pts Eligible to the study

26 Declined

84 participated

TVT-O

\begin{tabular}{|l|}
\hline 1 Month \\
80 pts \\
\hline $\begin{array}{l}6 \text { Months } \\
78 \text { pts }\end{array}$ \\
\hline 1 Year \\
78 pts \\
\hline 2 Years \\
78 pts \\
\hline 3 Years \\
77 pts
\end{tabular}

Failure to attend 0 Lost to Follow Up 3 Died 0

Failure to attend 0

Lost to Follow Up 2 Died 0

Failure to attend 0

Lost to Follow Up 0 Died 0

Failure to attend 0 Lost to Follow Up 0 Died 0

Failure to attend 0

Lost to Follow Up o Died 1 (Unrelated causes)
1 arruolated at the
first time, after excluded for
Parkinson's disease

2 pts removed sling for bladder obstruction

Figure 1. Flow chart. pts, patients; TVT-O, transobturator tension-free vaginal tape. 
three years, the checks found seven out of 17 patients completely dry. Ten patients reported the reappearance of mild stress incontinence, though they were still satisfied with the outcome of the operation; and two patients appeared not to have benefited from the procedure. These two patients were treated with urethral bulking agent. The results are summarized in Tables 2 and 3.

\section{Discussion}

TVT-0 surgery is a very effective and safe procedure that is effective in the long-term. The cure rate, about the SUI, was $91.02 \%$ at one year and $87.01 \%$ at three years, which means that TVT-0 seems to stand the test of time. Several publications have demonstrated the effectiveness of the retropubic TVT-0 surgical technique, ${ }^{10,-12}$ but very little data with longer follow-up periods is available on TVT-0 surgery and this is crucial for its management. ${ }^{11}$ Our success rate is certainly quite high, but we believe it is due to the elimination of women with mixed incontinence from the study, since this affects the final result greatly.

Cheng and Liu evaluated a population of women five years after the TVT-0 procedure. Even though they reported a very encouraging cure rate of $87.4 \%$, it must be taken into account that patients with preoperative $\mathrm{OAB}$ symptoms had not been excluded. ${ }^{13}$ The authors stated the complete disappearance of SUI occurred in nearly $90 \%$ of patients, but this is not at all relevant if the authors do not report the OAB symptom's persistence or de novo appearance rates.
Similarly, Groutz and colleagues reported a cure rate of $74 \%$ at 5 years in a group of 61 women who had undergone the TVT-0 procedure. ${ }^{11}$ However, the authors did not exclude women with mixed urinary incontinence, an important factor for healing after surgery.

Even Angioli et al. reported objective and subjective cure rates of $73 \%$ and $62 \%$, respectively, in their TVT-0 group. ${ }^{12}$ These 5 year outcomes were relatively less satisfactory when compared with those previously reported at one, three, and four years by most other authors, ${ }^{10,14,15}$ and also with our current data. However, one limitation of their interesting randomized study could be the very limited sample size, which likely influenced the cure rates reported. In fact, only 31 patients in the TVT-0 group completed the 5-year follow-ups, with a significant proportion of patients lost during the follow-up period (16\%).

At last the evidence for the effectiveness of TOT and TVT-0 when compared with each other is established over the short-term. Some studies report the two techniques but with a short follow-up, and show similar results, in terms of effectiveness, in the two approaches. However, studies are needed, with a follow-up greater, to know the long-term outcomes for both procedures. ${ }^{16,17}$

The onset of de novo OAB symptoms is one of the complications that most affect the final outcome. Some women may develop age-related OAB symptoms regardless of surgery, as it is an age related disease.

Our study recorded greater onset of de novo $\mathrm{OAB}$ than in published studies, especially in the early postoperative period.

We also tried to identify which independent factors might be involved in the risk of developing de novo $\mathrm{OAB}$, but no predictor factor was

Table 2. Results at follow-ups.

\begin{tabular}{lc}
\hline Follow up & Dry (\%) \\
1 month (80 patients) & 100 \\
6 months (78 patients) & 100 \\
\hline 1 year (78 patients) & 91.02 \\
2 years (78 patients) & 89.7 \\
\hline 3 years (77 patients) & 87.01 \\
\hline
\end{tabular}

Table 3. Results in patients with sphincter hypotonia (Valsalva leak point pressure $<60$ cm $\mathrm{H}_{2} \mathrm{O}$ ).

\begin{tabular}{lc}
\hline Follow-up & Dry (\%) \\
1 month (19 patients) & 100 \\
6 months (17 patients; 2 removed the sling for bladder obstruction) & 100 \\
\hline 1 year (17 patients) & 58.82 \\
2 years (17 patients) & 47.05 \\
\hline 3 years (17 patients) & 41.17
\end{tabular}

found.

Previous studies have reported de novo urgency rates ranging from $4 \%$ to $33 \%$ after the retropubic TVT procedure ${ }^{10}$ and ${ }^{18}$ but few works are available on the relationship between TVT0 and the onset of de novo OAB in the medium-term.

\section{Conclusions}

The results at three years of the study showed that TVT-0 is an effective option for the treatment of female SUI. The technique analyzed is confirmed as being safe when performed by trained professionals. It is a simple, non-invasive procedure with few risks and complications. The postoperative or de novo onset of $\mathrm{OAB}$ may be the most important clinical issue related to the TVT- 0 procedure.

Our data, however, show that the technique may also be used in patients with severe stress urinary incontinence with sphincter deficiency, taking into account that the outcomes may not be sustainable over the course of followups years later.

\section{References}

1. Plzak L, Staskin D. Genuine stress incontinence theories of etiology and surgical correction. Urol Clin North Am 2002;29:527-35.

2. Walters MD, Jackson GM. Urethral mobility and its relationship to stress incontinence in women. J Reprod Med 1990;35: 777-84.

3. Delancey J0. Why do women have stress urinary incontinence? Neurourol Urodyn 2010;29:S13-7.

4. Nilsson CG, Palva K, Rezapour M, Falconer C. Eleven years prospective follow-up of the tension-free vaginal tape procedure for treatment of stress urinary incontinence. Int Urogynecol J Pelvic Floor Dysfunct 2008;19:1043-7.

5. Olsson I, Abrahamsson AK, Kroon UB. Long-term efficacy of the tension-free vaginal tape procedure for the treatment of urinary incontinence: a retrospective follow-up 11.5 years post-operatively. Int Urogynecol J Pelvic Floor Dysfunct 2010;21:679-83.

6. Haylen BT, de Ridder D, Freeman RM, et al. An International Urogynecological Association (IUGA)/ International Continence Society (ICS) joint report on the terminology for female pelvic floor dysfunction. Int Urogynecol J 2010;21:5-26.

7. Avery K, Donovan J, Peters TJ, et al. A brief and robust measure for evaluating the 
symptoms and impact of urinary incontinence. Neurourol Urodyn 2004;23:322-30.

8. De Leval J. Novel surgical technique for the treatment of female stress urinary incontinence: transobturator vaginal tape inside-out. Eur Urol 2003;44:724-30.

9. Yalcin I, Bump RC. Validation of two global impression questionnaires for incontinence. Am J Obstet Gynecol 2003;189:98101.

10. Serati M, Ghezzi F, Cattoni E, et al. Tension-free vaginal tape for the treatment of urodynamic stress incontinence: efficacy and adverse effects at 10-year follow-up. Eur Urol 2012;61:939-46.

11. Novara G, Artibani W, Barber MD, et al. Updated systematic review and metaanalysis of the comparative data on colposuspensions, pubovaginal slings, and midurethral tapes in the surgical treatment of female stress urinary inconti- nence. Eur Urol 2010;58:218-38.

12. Angioli R, Plotti F, Muzii L, et al. Tensionfree vaginal tape versus transobturator suburethral tape: five-year follow-up results of a prospective, randomised trial. Eur Urol 2010;58:671-7.

13. Cheng D, Liu C. Tension-free vaginal tapeobturator in the treatment of stress urinary incontinence: a prospective study with five-year follow-up. Eur J Obstet Gynecol Reprod Biol. 2012;161:228-31.

14. Waltregny D, Gaspar Y, Reul 0, et al. TVT0 for the treatment of female stress urinary incontinence: results of a prospective study after a 3-year minimum follow-up. Eur Urol 2008;53:401-10.

15. Liapis A, Bakas P, Creatsas G. Efficacy of inside-out transobturator vaginal tape (TVT-0) at 4 years follow-up. Eur J Obstet Gynecol Reprod Biol 2010;148:199-201.

16. Stavros C, Ioannis V, Vasileios SI, et al.
Comparison of TVT, TVT-0/TOT and mini slings for the treatment of female stress urinary incontinence: 30 months follow up in 531 patients. Arch Ital Urol Androl 2012;84:129-36.

17. Ross S, Robert M, Swaby C, et al. Transobturator tape compared with tension-free vaginal tape for stress incontinence: a randomized controlled trial. Obstet Gynecol 2009;114:1287-94.

18. Novara G, Galfano A, Boscolo-Berto R, et al. Complication rates of tension-free midurethral slings in the treatment of female stress urinary incontinence: a systematic review and meta-analysis of randomized controlled trials comparing tension-free midurethral tapes to other surgical procedures and different devices. Eur Urol. 2008;53:288-309. 